\section{AN ANIMAL CONTROL OFFICER'S STORY: FROM ENFORCER TO EDUCATOR}

\author{
WILLIAM ERGAS PETERSON
}

Palo Alto, California

\section{On the Outside Looking In}

A childhood mernory of the animal control program in Palo Alto is a memory of the dogcatcher taking dogs away to the pound to be gassed. I remember a scene on the street from the middle 1960's of an animal control officer (at that time referred to as "poundmaster") chasing a small stray dog with a net and losing him or her, much to the joy of my

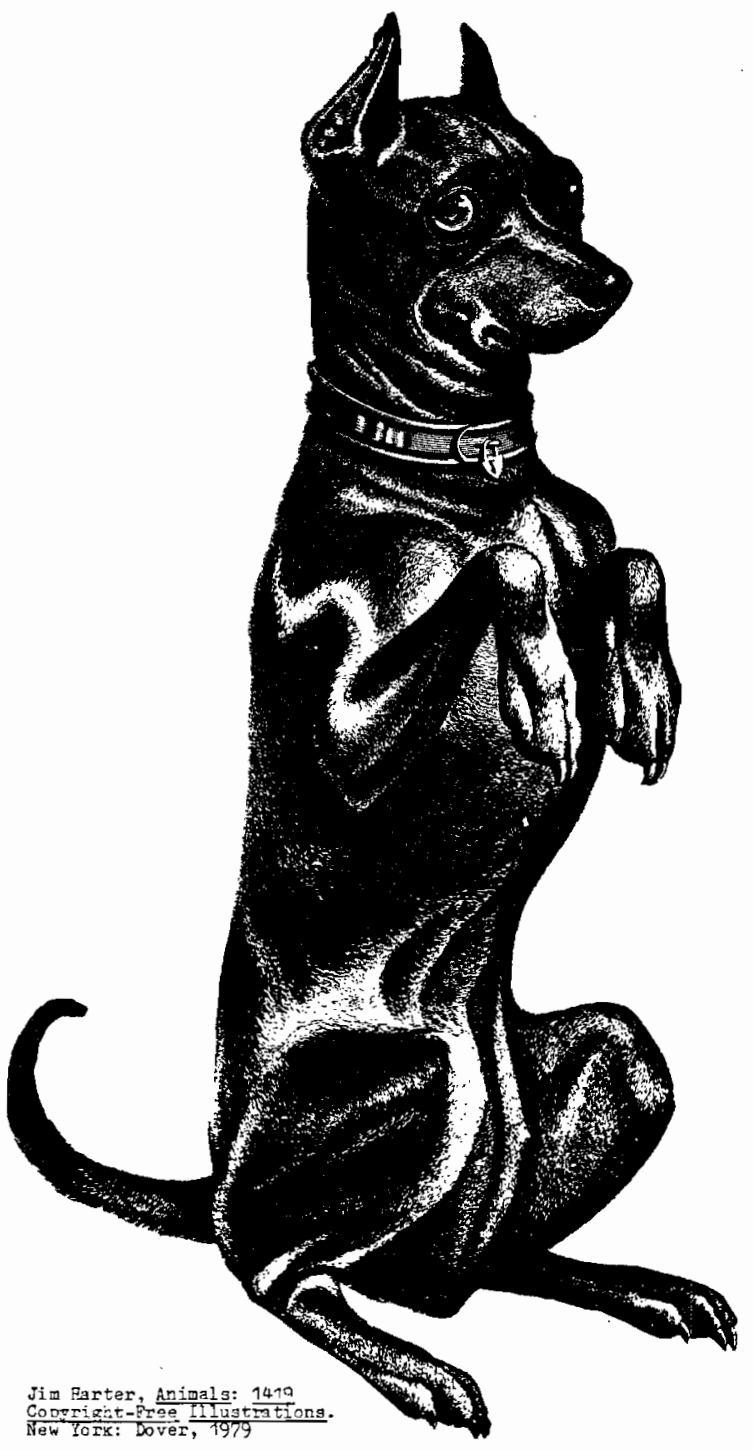

childhood companions, who cheered to the dog as it made its way from the clutches of death--or so we children believed. on a later occasion, we would feel nothing or ambivalence at the fate of a "free" kitten from a neighborhood litter that was taken to the pound when it was established that no one was willing to care for it. Such were my early years of animal control awareness. I concluded from these encounters with authority that the animal shelter was the necessary place for homeless pets. That there simply was no alternative to this essential evil short of an even greater unpleasantness on the street through injury, sickness, or starvation.

In 1974, at age 15, I took a step closer from the outside looking in and became a volunteer at the City of Palo Alto Animal Services Center--the animal shelter's formal name. By this time, the poundmasters were called "animal control officers" and the words "pound" and "shelter," uttered within earshot of the shelter director, elicited a response that left a person with the feeling of having comitted a great social blunder. And the staff never dared to address the "Animal Services Superintendent" ,for what they understood him to be: the chief dogcatcher for Palo Alto.

It was a cosmetic era for Palo Alto. Other city offices had titles which differed from the traditional. The city dump became the Refuse Center. The city sewer became the Water Quality Control Plant. Hence came the renaming of the dogpound, another city office with unpleasant connotations. "Animal Ser-

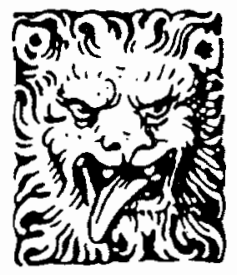

\section{AUTO -}

BIOGRAPHY 
vices" certainly has a cleaner ring, and this sound lent harmony to the freshly painted dogcatchers' trucks, which had recently gone from brown to white.

As a volunteer at the shelter from 74 to 176, I worked for the Wildlife Rescue Team, a separate entity from the City, though housed in its offices and reliant on its good will. The Rescue Team was a pilot project established by five private citizens with the blessings of City and state to rehabilitate and release distressed native wild animals. It was viewed by some of the animal control officers with a degree of hostility directly proportional to their degree of contact with the volunteers, who were collectively identified as little old ladies in tennis shoes with an unrealistic view of people's relationship to other animals.

This hostility, when finally expressed in a series of stormy confrontations between volunteers and staff, was ultimately to lead to the animal awareness education of the latter, though the change was slow, grudging, and subject to relapse. An early example of this education was seen in the transportation and handling by animal control officers of injured birds to the Rescue Team. The first officer to bring a wild bird in a wire cage was advised by the volunteers that a cardboard box, towel, or paper bag was far preferable for avian confinement and delivery, for, it was explained, the bird is less likeIy to break feathers this way and is less subject to visual stimuli that might cause it further mental trauma.

The impact of this dissertation upon the 26 year veteran animal control officer, who had lived his life with an ethic of animals as chattel to be managed at his convenience, was at first indignation directed toward the upstart for daring to teach the unteachable, and later disgruntled acceptance following an order from the shelter director and the birth of the cardboard bird-box at Animal services. Behavior had been modified, however cameo the appearance in relation to the real feelings of the officer toward animal care. Bitter exchanges from like encounters would persist, but the two opposites would come together out of necessity to make it through the workday. Love it or leave. They were now a team.

Another substantial modification to the practices of the animal shelter in Palo Alto came in the form of a city-funded spay and neuter clinic, housed in the shelter, which opened for business three years before wildlife Rescue arrived.

In conversations with the shelter's animal attendant/euthanasia technician-yes, that job in Palo Alto in 1974 was delegated to one person!--I was told of the days prior to the advent of the clinic, of the spring and surmer weeks spent in the killing of hundreds of puppies and kittens, and available kennel spaces taxed to their limit. It impressed me as an inconceivable event in the present-day shelter, which prides itself on a "no time limit" policy for adoptable animals. And though now (now being 1974) the shelter had begun the transformation from a killing facility struggling against an ever-resurging element to a seemingly caring facility dedicated to the preservation of the quality of that element, the attitude of animal control officers and other staff remained largely that of an army of occupation enforcing the will of a great, grey THEY upon an uneducated, unknowing public. This attitude was typified in the accepted manner of euthanasia at that time practiced at Animal Services and throughout California: the high-altitude decompression chamber.

"The high-altitude decompression chamber, " the use of which was outlawed in 1976, was the name given to this airtight, castiron cylinder, about the combined size of four water boilers, that held dogs and cats in what would be their last physical boundaries. The animal to be killed by this method was placed in the chamber by way of a cage which slid into the chamber. The chamber door would then be shut and the air pumped out of the chamber until the animal, sufficiently deprived of oxygen, collapsed in convulsions to the cage-floor. The chamber had a small porthole-shaped window which allowed the animal attendant a view of the progress of death. Animals were held in the chamber 15 minutes after death. The turn of a valve allowed air to return to the chamber, and it did so with an ear-shattering blast that seened to accentuate the finality of what had been done. Upon opening the chamber door, it was not unusual to find blood oozing from the mouth and ears of the dead, their paws gripped to the sides of the wire insertcage, and their faces frozen in contorted expressions of pain. It was a very neat process for the animal attendant, however. No handling of the subject was required. The worker could walk away from the chamber after 
pumping out the air and not return until 15 minutes later to inspect the result.

Those who enployed this chamber strongly advocated it. I was assured of its humanity and convinced by its users that the animals did not suffer. I failed to take into account the opinions of the subjects of the chamber. As illustrated in their expressions, this was not a painless way to die.

We were convinced of the humanity of the chamber. We couldn't understand the reasoning of the people who campaigned against it. They were the unknowing public, engaged in an exercise of disinformation and propaganda. our attitude was that we knew more, that we knew best. And this attitude pervaded our thinking to the detriment of our relationship with human animals in the 1970's. Even our limited sensitivity for animals was lost when people were the animals to be dealt with. Discrimination at Animal Services took the shape of a kindness that was shared with at least' some animals there but withheld from the public. Since our work invariably touched human beings, the potential for abuse of humankind was staggering. The occasion of abuse was regular. The damage to human thinking was incalculable.

As Wilalife Rescue volunteer, I observed the attitude. As animal attendant and then as reception-desk worker, I participated in the attitude. Five years after arriving at Animal Services, and fully indoctrinated in its procedures, I was hired as one of its animal control officers.

\section{My Years as an Animal Control Officer}

The animal control officer in Palo Alto is a member of the city's police department. When I took on the job in 1979, I was not unfamiliar with its procedures. I had spent part of my volunteer time with animal control officers on the road and had come to understand their philosophy. It was my first contact with a group of people who were largely of a cynical, paramilitary manner. Their association with government at that time made them legitimate and right in my eyes, and I adopted their contempt for a broad spectrum of society. Lacking both the skills of the law enforcement profession and the requisite authority from the city to perform their work, the animal control officer was not well-equipped to investigate or prosecute serious crimes against animals.
This lack of skills was promulgated by the city's hiring policy. Prospective animal control officers needed little more than a driver's license and a high school diploma to be considered for a position with the city and, once hired, were expected by the city police department to perform as "quantitative workers."

The emphasis was on law enforcement quotas, but the word "quota" had a negative impression upon the community; therefore, the phrase "target objective" supplanted the former label of our purpose. Officers were in a perpetual state of anxiety from the pressures of competition with other officers in pursuit of their monthly target objective for penalty citations, written warnings, and dogs captured. The effect of this situation upon the animals and the public was evident in the areas where officers are influential: animal capture methods, animal sheltering and care, comunity relations, and humane education.

Animal capture methods under an administration that emphasized quantitative productivity resulted in the pursuit of stray dogs to excess. Officers were expected to round up 30 to 40 stray dogs per month--a figure that compelled officess sometimes to take unattended dogs from the un-enclosed front yards of their owners, though this was later made illegal. A more popular method of capture of the elusive stray was the running of dogs to a point where exhaustion allowed an officer to contain them. This procedure was employed regularly in the case of dogs that could have led the officer to their home, if only they were given safe passage to do so. The officer, out of selfish concern for his/ her monthly target objective, would often attempt to cut off that passage, for to allow

the dogs to pass would afford them a chance to escape or return home, where contact with the dog's owner would result in a lengthy negotiation over the administration of a penalty for having a dog off-leash. Therefore, in the interest of time and productivity, safe passage was blocked by confronting the dogs and scaring them in one direction and then driving ahead of them to scare them back the other way. The dogs could be effectively contained within a radius of several city blocks until, tired from the chase, they would try to duck out in a dead end lot or yard, or collapse from stress--which is why this method was especially favored in summer. The officer could at that point easily effect 
a capture.

A variation on the theme of extraordinary animal capture methods was seen in one season of particular difficulty with the control of a feral dog community living in the city's bay marshland preserve. There were four dogs that became skilled hunters of ground squirrel, jack rabbit, and pheasant, and their daily hunt often took them across an airport runway in pursuit of game.

The standard operating procedure of pursuit till exhaustion was not effective in this rural sector of the city, and chemical capture (tranquilizing) methods were not available to animal control, nor were staff skilled in their application. There was one "humane" cage-trap at Animal Services that was large enough to hold a dog, but it was in disrepair, and at that time the shelter director was disinclined to repair or replace this hardware. The existence of the dogs, together with a lack of practical supplies and a complaint from the airport, were the contributing factors in a decision by administration to shoot the dogs. The final approval of this exercise came from the chief of police, utilizing the city ordinance which sanctions the "destruction" of any animal deemed to be harassing or threatening wild animals in the preserve.

The shooting was a fiasco. The police officers assigned to the detail were skilled marksmen, but they were also anxious marksmen, and the dogs were taken on not in the open field of the marshland near the airport but in the center of an industrial park on the boundaries of the preserve. The shooting caused the minor injury by shotgun blast of one dog and the escape of the entire pack. Complaints from businesspeople shocked out of their offices by gunfire at the start of their workday brought a quick end to the project.

This failure initiated phase-two extraordinaire: leg-hold traps. A biological consulting firm was retained by the city in this next action. The traps were a modification of the standard leg-hold trap; an opening in the clamp structure prevented the breaking of the leg and allowed only for its restraint. Imagine being in handcuffs that are locked on your wrists too tightly , and you can simulate the feeling of this trap. During the month of this project, two dogs were caught in the traps. In each instance, the dogs were held fast by the toes of one of their hind legs. In one instance, a dog pulled the trap from its anchoring and tried to escape by dragging his/her newly acquired handicap. This dog was tracked down and captured.

Not long after the trapping exercise, an aninal control officer patrolling the marshland stumbled upon a den of the feral dog community. Three dogs were captured, including two who were pregnant. This effectively limited the dogs' presence and activities in the area; the airport complaint was satisfied; and attitudes returned to a less frantic state. Still, the pressure that gave birth to these practices--the pressure of quotas and quantity before quality--remained in force. The abuse was not limited to fourlegged members of the animal kingdom, though they bore the brunt of the abuse.

Pressure to produce also means pressure to make time to produce, and this means working as little as possible in the places at Animal Services where productivity was not recognized. A particular area of neglect was the care given to captured dogs by their captors. Dogs impoumded were dogs ignored beyond their direction to a cage and the filing of their capture record. I am referring in this instance to the non-care of the dog by the animal control officer, for the shelter kennel attendants have largely been good providers to their charges. Basic incoming care such as booster vaccinations and feeding were not in practice. Rough or improper handling of the animals sometimes occurred, and in one instance of venting, an animal control officer who could not get a dog to keep still actually kicked the dog. Although this deplorable happening was an isolated occurrence (which is little consolation for the dog that was kicked), it was not out of character with the conflict that officers experienced between time needed properly to care for an animal and actual time allotted for that care.

\section{The Officer as Educator}

These generally were the practices that I witnessed or participated in at Animal Services. It propagated an unhappy character in the workers, and few lasted beyond a year in the job. From 1974 to 1985, the five positions of animal control officer were filled 17 times. The position was proving to be a revolving door to nowhere--a place to 
exist and draw your pay while waiting for something better to come along. It was not for lack of brilliant minds occupying the position, for many bright people were among the 17 who came and went. However, the emphasis of the shelter administration, that is, the police department, was on numbers and totals, on legislation before education. The relationship between shelter and community suffered greatly from this circumstance.

Animal control officers, in addition to catching dogs, were expected to issue citations for infractions of the city code. The laws of primary enforcement were the leash and license requirements for dogs. These laws, on the books since the 1950's, were written and voted into existence by a comnunity attempting to control its canine traffic and the possible spread of human and animal diseases. Largely ignored by the police through the 1960's, the leash and license laws were for the most part supported by the common courtesy that the people had for each other. By the late '60's and early '70's, an influx of dog-owning citizens and an attitude contrary to the minds of those who wrote the law began to infringe on the rights and tolerance of the non-dog-owning populace. The result was the adoption of a program of active enforcement of the city code. In 1972, Palo Alto animal control officers were for the first time given authority and orders to

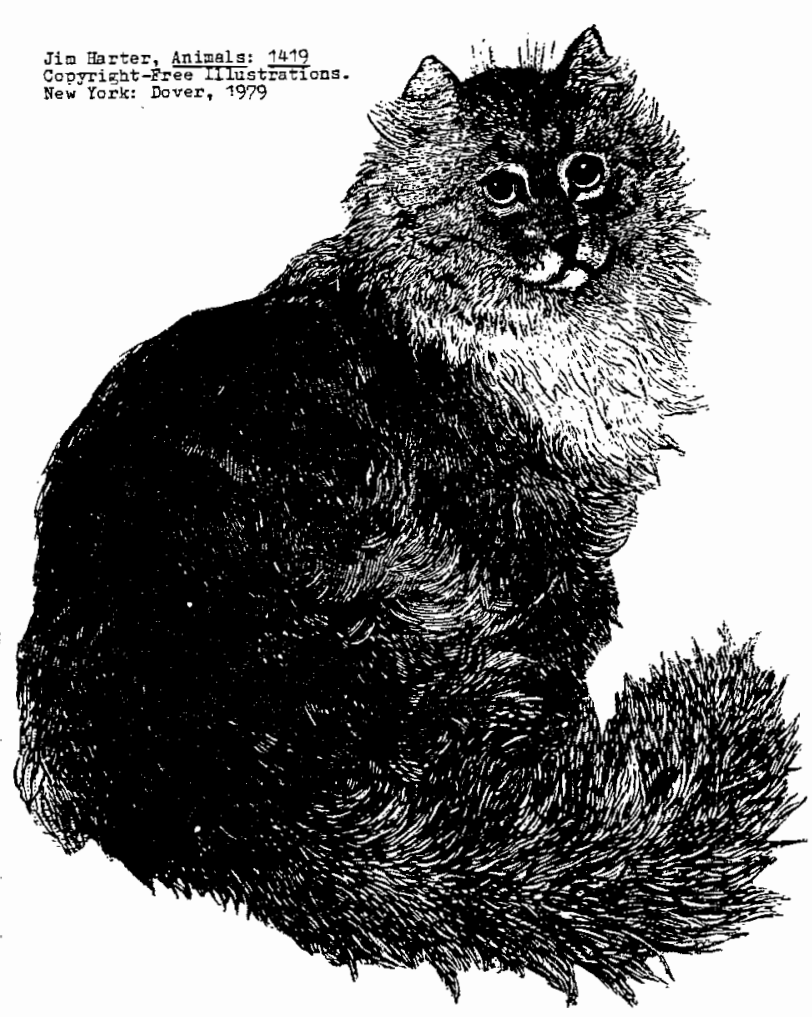

cite leash and license law violators. The result was a human relations nightmare.

Untrained in the finer points of crisis intervention and defusion of hostility, the animal control officers entered their city each workday like an army of occupation. It was life in wartime for dog owners as well, both responsible and irresponsible. People whose dogs were six feet away from them but off-leash were as likely to receive the $\$ 40$ fine as were those whose dogs were out unattended and roaming blocks away from home. People cited for breaking the law were dealt with impersonally and without empathy for their situation or aid for its correction. The animal control officer either did not wish to help or did not see it as the responsibility of an animal control officer to solve the pet owner's problem. The only problem to be solved by the animal control officer was the problem of meeting the target objective of two tickets a day. Who could waste hours engaged in remedial work with an errant dog owner when the time could be spent writing another citation? This is the way our minds worked.

At best for the animal control officer, those who were cited aoquiesced sadly and with resignation. At worst, they put up a fight. Calling out the police to help an animal control officer issuing a citation was a weekly happening. Bitterness separated officer from community. Quantitative competition separated officer from officer. Both sides hated the administration, and while one side was powerless to change procedures, the other was intimidated and impotent. Lacking unity, courage, and tactics, the divided house of animal control stood on feet of clay. The city office established for the service of animals had become the office of dehumanizing, obsessive/compulsive actions toward animals, both two and four-legged.

Four years and countless migranes down the road from my entry into this vicious circle, I decided to make a change in $m y$ applications of law. I had been one of the city's most productive, paper-pushing animal control officers. In my first year on the job, I had captured 300 dogs and written 400 citations. Three more years of similar activity followed. After four years of this, I assessed the status of my position and the impact it was having on my life and my city. I saw all that I have heretofore related. 


\section{Then I stopped writing citations.}

Next, I started taking dogs to their homes, rather than to the shelter.

I did not ignore the errant dog owners, nor did I avoid the places where I knew they could be found. What I started to do was to talk with, rather than at, these people, to understand why they chose to care for their animals in the way they did, and to attempt to reach agreement between their values and the law that would at the same time satisfy the interests of the non-pet-owning people. Two years later, this change from an enforcement to an educational position has resulted in compliance with the law to the satisfaction of the community. Pet owners do not irresponsibly run their animals through the city just because officers now rarely issue citations. When problems do arise, their existence is attributable to the animal owner lacking an awareness of the problem or possessing an attitude of animal care in conflict with the law. While in days past this awareness could be increased and an attitude changed through the negative stimuli inherent in a citation, today a like accomplishment is being achieved through education in the field by the animal control officer. Also, a greater degree of goodwill exists between officer and community, where once there was little or none. How this plan will progress is yet to be seen, for the project is in its infancy. However, its short-term accomplishments are evidenced by the love of the job demonstrated by the animal control officers who employ the new philosophy. A decreased rate of attrition of officers is probable, because we have eliminated the underlying reason for the majority of resignations: the administration's pressure to produce quantitative results.

Through my change of tactics at work we have discovered that an officer will not be fired or harassed out of the job for not meeting the target objectives of the city's government. While I have invoked a mild displeasure from the administration and have probably voided my chances for promotion within their system, beyond this there is little else they can do to me, and they cannot take away my livelihood. This, then, is the drawback for those in the animal control profession who are here in part to seek advancement, for if they attempt to apply an educational approach where before an enforcement attitude has existed, they are likely to neet impediments fram the architects and proponents of the former system. In short, they will irritate the hell out of their bosses, especially when it works, and it will work wherever people possess a respect for life. This premise is illustrated in the following two case histories.

"Mieu" is a cat that until recently was living a semi-feral existence out of the backyard of the Palo Alto home and family that she had adopted. This family of Mieu's choosing provided her with food and water but otherwise allowed her to fend for herself. Against the odds that face an unowned domestic cat, Mieu not only survived but also found time and energy to raise two litters of feral kittens. It was the prospect of another kitten season and the probablt fate of the offspring that prompted a neighbor of Mieu's family to report the situation of her care to Animal Services.

Under the circumstances of Palo Alto's enforcement approach, her adopted family would have been identified as the owner and subject to citations for allowing a cat to breed beyond one litter per year and for maintaining more than three cats on their property. The burden would have been on Mieu's owners to correct the situation. The participation of the animal control officer beyond enforcement would have been virtually nonexistent. In this case, the education approach was employed. Mieu's owners were advised of the law, but rather than having a citation follow this admonition, the officer offered to assist in problem solving, and this offer was accepted. Mieu's remaining litter of feral kittens was impounded, and Mieu was taken to the Animal Services' spay clinic for an ovarihysterectomy. The kittens were evaluated and their fate sadly determined. Deprived of human contact during their formative weeks, frightened into depression at living in cages, and hostile to human contact, they were judged unadoptable and euthanized.

Could we have tried raising them to maturity, spaying and neutering them, and then releasing them to welcoming neighborhoods? In a shelter with more extensive resources, this could certainly happen. The resources in this instance were Iimited to Mieu and her future. Her adopted owners chose to adopt her. They financed her surgery and purchased a safe, break-away collar for her. A free pet identification tag was 
given to her under the city's voluntary pet tag program. She has been given indoor access to her owners' home and a guarantee from her owners of her rights: the right to exist, the right to enjoy her world as we do ours, the right to be provided for as she provides, the right to all essential medical and mental accommodation, and the right to kindness and faimess. Such is this success of education.

"Scruffy Dithers" is the Palo Alto streetpeople's dog. Wandering the city without guarantee of shelter and wary of society's mainstream participants, Scruffy found a group of kindred spirits under the railway bridge at San Francisquito Creek and El Palo Alto. Scruffy has been the occasion of several instances of leash law violations, but rather than coming down on his caretakers with an enforcement attitude, an educational tactic has been adopted which today finds Scruffy with access to a home, vaccinated for rabies, and wearing an identification tag. The major stumbling block with Scruffy has been with leashes. Scruffy is not confortable when leashed, and in spite of free leashes and meetings between officers and owners, they have not changed his behavior to a mutually favorable end.

In spite of his street wisdom, it is feared that Scruffy will meet tragedy one day on the road from a less perceptive and illtimed autombile. Should that happen, then education in this instance will have failed, and it will be argued that Scruffy could have been saved by an enforcement tactic that would have taken him away from his owners and attempted to find him a more responsible, providing home. Yet, everyday that Scruffy lives in defiance of the established order is another day that he has provided love for his people and flourished in the environment of his choosing. It is a risk, and perhaps a revolutionary endeavor to allow it to continue. Also, it is a choice made in consideration of the public good, and after weighing possibility and reality, we have chosen reality and its untold future. our decisions in this case have been governed by the greatest allowance for freedom of living interests. If we fail in this, we go down with, rather than without, our principles. In that form, failure is not total. An element of success is retained, that element which finds us remaining true to the realm of our selves.

\section{Conclusion}

All of this is in keeping with a natural progress of society. For the animal control officer to become the animal awareness educator is for the parent to become the peer, and to allow for a trend toward greater individual respect and responsibility for the administration of personal freedoms. By letting a community govern themselves with their campassion and common sense, we extend a degree of elevation and humanity for all; we also take a chance that we shall fail. Yet, after the particular failure of an animal control police state in the 1970's and weighing that history against the progress of animal awareness education in Palo Alto today, I an sure that we are making the correct choice, a choice that reflects the best of humanity. In my estimation, that is the measure of success for the animal control officer as animal awareness educator.

\section{The First Speciesist}

The earth has never cried for blood

nor the seas for sacrifice.

The skies send winds with

or without

propitiation.

Thirsty god-masks

mask man's thirst

for blood as he dances 'round his sacrificial fires

his cooking fires

his Bunsen burners

PAULETIE CALUEN

and his microwaves.

Nutley, New Jersey

For whom does he dance? 